\section{Recurrent Drug-Induced Liver Injury With Cetirizine and Amoxicillin-Clavulanate Potassium}

Vilà-Nadal $\mathrm{G}^{1}$, Lleonart Bellfill $\mathrm{R}^{1}$, Martí Garrido $\mathrm{J}^{1}$, Baliellas Comellas $\mathrm{C}^{2}$, Corominas Sánchez $\mathrm{M}^{1}$

${ }^{1}$ Allergology-Internal Medicine, Hospital Universitari Bellvitge IDIBELL, L'Hospitalet de Llobregat, Barcelona, Spain

${ }^{2}$ Gastroenterology Department, Liver Unit, Hospital Universitari de Bellvitge, IDIBELL, Universitat de Barcelona, L'Hospitalet de Llobregat, Barcelona, Spain

J Investig Allergol Clin Immunol 2019; Vol. 29(4): 321-322 doi: $10.18176 /$ jiaci.0397

Key words: Drug-induced liver injury. Cetirizine. Amoxicillin-clavulanate potassium. Hepatotoxicity.

Palabras clave: Enfermedad hepática tóxica inducida por drogas. Cetirizina. Amoxicilina/clavulanato de potasio. Hepatotoxicidad.

A 35-year-old woman with acute otitis media was treated with amoxicillin $1 \mathrm{~g}$ every 8 hours for 8 days. Treatment was switched to amoxicillin-clavulanate potassium $875 / 125 \mathrm{mg}$ every 8 hours for 4 days because of lack of response. When the patient finished the course of antibiotics, she experienced general malaise, nausea, dark urine, and acholia. Physical examination revealed jaundice. The patient denied any history of alcohol intake, recreational drugs, and other medication (prescription, over-the-counter, or herbal preparations). She had no known drug allergies or underlying diseases.

Laboratory blood tests showed increased levels of aspartate aminotransferase (AST) $1798 \mathrm{IU} / \mathrm{mL}$, alanine aminotransferase (ALT, $2130 \mathrm{IU} / \mathrm{mL}$ ), alkaline phosphatase (ALP, 132 IU/L), $\gamma$-glutamyl transpeptidase (GGT) $118 \mathrm{IU} / \mathrm{L}$, total bilirubin $(6.31 \mathrm{mg} / \mathrm{dL})$, and direct bilirubin $(1.31 \mathrm{mg} /$ $\mathrm{dL}$ ). The leukocyte count was normal, with no eosinophilia, and no abnormalities were detected for glucose levels, thyroid hormones, protein profile, and prothrombin index.
The antinuclear antibody (ANA) titer reached $1 / 320$, and the anti-smooth muscle antibody (anti-SMA) and anti-liver kidney microsome antibody (anti-LKM) titers were negative. Serological tests for hepatotropic viruses (IgM anti-HAV, HBsAg, IgM anti-HBc, anti-HCV, HCV RNA) and anti-HIV antibodies were negative. Abdominal ultrasound indicated a normal liver with normal biliary tract. The episode was attributed to amoxicillin-clavulanate potassium. The causality score was 7 (probable) according to the updated scale of the Roussel Uclaf Causality Assessment Method (RUCAM/ CIOMS) [1].

The patient recovered completely 3 weeks after stopping treatment, and values for liver function returned to normal.

Thirteen years earlier, the patient had experienced a similar episode with general jaundice and laboratory blood tests showing an increase in AST (1873 IU/mL), total bilirubin $(8.82 \mathrm{mg} / \mathrm{dL})$, and an international normalized ratio of 2.09. On that occasion, the patient was admitted to hospital because of severe liver impairment. The ANA titer reached $1 / 160$, with negative anti-SMA and anti-LKM titers. Other causes of liver injury were excluded: results for IgM anti$\mathrm{HAV}$, IgM anti-HBc, anti-HCV, HCV RNA, IgM CMV, and IgM EB were negative, and findings for thyroid hormones and protein profile were normal. The results of the ultrasound examination were normal. The score on the RUCAM/CIOMS scale was 7 . The patient was diagnosed with acute hepatitis of unknown etiology.

On that occasion, the only treatment involved was cetirizine $10 \mathrm{mg}$. The patient had started treatment with this antihistamine a month earlier owing to seasonal allergic rhinoconjunctivitis. Cetirizine was withdrawn when she was admitted to hospital. Her progress was good, and laboratory results returned to normal at 6 weeks. The only medication she reported having taken between the 2 episodes was naproxen (very sporadically).

Based on the findings and the RUCAM/CIOMS scale, the patient was diagnosed with drug-induced liver injury (DILI), probably secondary to amoxicillin-clavulanate potassium and cetirizine.

The laboratory results for the 2 DILI episodes can be seen in the Table.

Table. Liver Vest Values in the 2 Episodes of DILI

\begin{tabular}{|c|c|c|c|c|c|c|c|c|c|c|}
\hline & \multirow{2}{*}{\multicolumn{5}{|c|}{$\begin{array}{c}\text { DILI } 1 \\
2004\end{array}$}} & \multicolumn{5}{|c|}{ DILI 2} \\
\hline & & & & & & \multicolumn{4}{|c|}{2017} & \multirow{2}{*}{$\frac{2018}{\text { Jul } 10^{\text {th }}}$} \\
\hline & Jun $12^{\text {th }}$ & Jun $16^{\text {th }}$ & Jul $12^{\text {th }}$ & Jul $30^{\text {th }}$ & Oct $4^{\text {th }}$ & Jul $3^{\text {rd }}$ & Jul $5^{\text {th }}$ & Aug $7^{\text {th }}$ & May $3^{\text {rd }}$ & \\
\hline $\operatorname{ALT}(\mathrm{N} \leq 34 \mathrm{IU} / \mathrm{L})$ & 1873 & 1560 & 90 & 30 & 16 & 342 & 2130 & 34 & 15 & 15 \\
\hline 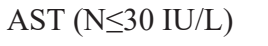 & 1500 & 1260 & 57 & 28 & 10 & 162 & 1798 & 31 & 10 & 9 \\
\hline $\mathrm{TBL}(\mathrm{N} \leq 1 \mathrm{mg} / \mathrm{dL})$ & 8.8 & 18.6 & 2.4 & 0.8 & 0.7 & 1.7 & 6.3 & 1.1 & 0.7 & 0.7 \\
\hline 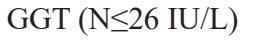 & 64 & 72 & 78 & 18 & 15 & 152 & 118 & 53 & 15 & 13 \\
\hline ALF $(\mathrm{N} \leq 104 \mathrm{IU} / \mathrm{L})$ & 120 & 120 & 96 & 65 & 62 & 114 & 132 & 66 & 62 & 60 \\
\hline INR $(\mathrm{N} \leq 1.2)$ & 2.0 & 1.7 & 1.2 & 0.9 & 0.9 & 1 & 1 & 1.1 & 0.9 & 0.9 \\
\hline
\end{tabular}

Abbreviations: ALT, alanine aminotransferase; ALP, alkaline phosphatase; AST, aspartate aminotransferase; DILI, drug-induced liver injury; GGT, $\gamma$-glutamyl transpeptidase; INR, international normalized ratio. 
Liver injury has several causes (eg, infections, toxic substances, autoimmunity, and drugs). DILI is considered when a possible culprit drug is present and other causes of liver injury have been excluded. This diagnosis is confirmed based on 1 of the following 3 criteria: (1) ALT $\geq 5$ times the upper limit of normal (ULN), (2) ALP $\geq 2$ times ULN, (3) ALT $\geq 3$ times ULN plus total bilirubin $\geq 2$ times ULN [2].

Although hepatotoxicity has been described with virtually all drugs, DILI represents fewer than $1 \%$ of cases of acute liver injury. An incidence of 13.9 to 19.1 cases per 100000 inhabitants has been reported [3]. In a broad review of published series of DILI, the authors found that $34.2 \%$ of cases of suspected DILI had alternative causes of liver injury that confounded the DILI diagnosis and suggest that a diagnosis of DILI should be established using a score system such as the RUCAM/CIOMS scale [4]. Although this scale has its limitations, it can sometimes help establish causality in DILI. In the case we report, other causes of liver injury were excluded, and the RUCAM/CIOMS scale indicated probable causality in both episodes.

Susceptibility to DILI is believed to result from interplay of multiple factors, including the structure of the drug, the patient's genetic background, the influence of underlying diseases, and associated medications [5]. Nevertheless, a genetic basis for DILI has not been determined [6]

In the present case, taking into the account the positive ANA results in both episodes, we suspect the possible involvement of an autoimmune mechanism not yet clarified. Lucena et al [7] reviewed all registered cases of DILI in Spain over a period of 15 years and found that the frequency of individuals experiencing 2 DILI episodes caused by different drugs was $1.21 \%$. Researchers found that second episodes of DILI were more likely to be associated with features of autoimmune hepatitis; however, it remained uncertain whether this was drug-induced unmasking of true autoimmune hepatitis or DILI with an autoimmune component. In addition, the drugs were not related in structure or function in only 2 patients, as occurred in the case we report here: the patient first had DILI due to cetirizine and then a second episode of DILI a few years later due to amoxicillin-clavulanate potassium. According to the US DILI Network [8] and other publications [3], DILI is mainly caused by antimicrobial agents, with amoxicillinclavulanate being the most prominent one [8]. Of note, amoxicillin without clavulanate does not appear in the top 10 major individual agents causing DILI [9]. However, fewer than 10 cases of cetirizine-related acute hepatitis have been reported in the literature [10].

Given that the pathophysiology of the DILI mechanism is not yet known, a specific diagnostic test could not be performed. It is not clear weather reintroducing the suspect drug would reproduce the same liver damage.

Finally, the patient was advised to avoid both medications For future prescriptions, including other antibiotics and antihistamines, we recommended monitoring liver function during administration and the following weeks.

Recurrent DILI caused by drugs with different chemical structures is very rare. To our knowledge this is the first case of recurrent DILI with 2 different drugs: amoxicillin-clavulanate and cetirizine.

\section{Funding}

The authors declare that no funding was received for the present study.

\section{Conflicts of Interest}

The authors declare that they have no conflicts of interest.

\section{References}

1. Danan G, Teschke R. RUCAM in Drug and Herb Induced Liver Injury: The Update. Haybaeck J, ed. Int J Mol Sci. 2016;17:14.

2. Aithal GP, Watkins PB, Andrade RJ, Larrey D, Molokhia $\mathrm{M}$, Takikawa $\mathrm{H}$, et al. Case definition and phenotype standardization in drug-induced liver injury. Clin Pharmacol Ther. 2001;89:806-15.

3. Björnsson ES, Bergmann OM, Björnsson HK, Kvaran RB, Olafsson S. Incidence, presentation and outcomes in patients with drug-induced liver injury in the general population of Iceland. Gastroenterology. 2013;144:1419-25.

4. Teschke R, Danan G. Drug induced liver injury: Alternative causes in case series as confounding variables. Br J Clin Pharmacol. 2018;84:1467-77.

5. Verma S, Kaplowitz N. Diagnosis, management and prevention of drug-induced liver injury. Gut. 2009:58:1555-64.

6. Jurado-Escobar R, Perkins JR, García-Martín E, Isidoro-García M, Doña I, Torres MJ, et al. Update on the Genetic Basis of Drug Hypersensitivity Reactions. J Investig Allergol Clin Immunol. 2017:27:336-45.

7. Lucena Ml, Kaplowitz N, Hallal H, Castiella A, GarcíaBengoechea $M$, Otazua $P$, et al. Recurrent Drug-Induced Liver Injury (DILI) with different drugs in the Spanish Registry: The dilemma of the relationship to autoimmune hepatitis. J Hepatol. 2011;55:820-7.

8. Chalasani $N$, Bonkovsky HL, Fontana R, Lee W, Stolz A Talwalkar J, et al. Features and Outcomes of 899 Patients With Drug-Induced Liver Injury: The DILIN Prospective Study. Gastroenterology. 2015;148:1340-52.

9. Ahmad J, Odin JA. Epidemiology and genetic risk factors of drug hepatotoxicity. Clin Liver Dis. 2017;21:55-72.

10. Coskun A, Yavasoglu I, Yasa MH, Culhaci N, Yukselen V. Cetirizine-induced hepatotoxicity: case series and review of the literature. Gastroenterology Report. 2018;6:228-30.

Manuscript received November 8, 2018; accepted for publication April 2, 2019.

Gemma Vilà-Nadal

Allergy \& Clinical Immunology 4th Floor Fulham Wing Royal Brompton Hospital Sydney Street London SW3 6NP, UK E-mail: G.Vila-Nadal@rbht.nhs.uk 